\title{
TWO ANALYTICAL METHODS FOR OPTIMISING SOLAR PROCESS HEAT SYSTEM USED IN A PASTEURISING PLANT
}

UDC: $502.21: 523.9$

Original scientific paper

https://doi.org/10.18485/aeletters.2021.6.4.4

\author{
Rajab Ghabour ${ }^{1 *}$, Ljubiša Josimović ${ }^{2}$ Péter Korzenszky ${ }^{3}$ \\ ${ }^{1}$ Hungarian University of Agriculture and Life Sciences, Mechanical engineering doctoral school, Gödöllö, \\ Hungary \\ ${ }^{2}$ Ljubiša Josimović, Academy of Vocational Studies Southern Serbia, Department of Technological Art Studies, \\ Leskovac, Serbia \\ ${ }^{3}$ Hungarian University of Agriculture and Life Sciences, Institute of machinery and informatics, Gödöllö, \\ Hungary
}

\begin{abstract}
:
With more than $27 \%$ of the final heat demand in Europe consumed by the industrial sector, solar heat for the industrial process is one of the hottest topics nowadays, leading to many initiatives to make pilot projects in central and southern Europe. This paper analysed two analytical methods to optimise the essential working parameters (solar collectors, glycol ratio, volume flow rate, relative tank capacity, and tank height/diameter ratio) in a pasteurising plant located in Budapest, Hungary. The first method is an analytical approach to determine the optimum values considering the other variables at fixed levels. In contrast, the other one is linear modelling using response surface method RSM and R script coding program to identify the most influential factors using Pareto plots and then discussing the most important two factors' interactions. This research aims to identify which method is better for optimising solar heat for industrial (SHIP) systems. The paper compares the previously mentioned methods, and the results are compared with the results from the other authors. As a result, all factors showed similar magnitudes in both methods except for relative flow rate which was neutral in the analytical method and positive in the RSM.
\end{abstract}

\section{ARTICLE HISTORY}

Received: 20.06.2021.

Accepted: 11.11.2021.

Available: 31.12.2021.

\section{KEYWORDS}

Solar Thermal, T*Sol, RSM, R Script, Process Heat.

\section{INTRODUCTION}

Solar process heat is defined as hot water production using solar thermal collectors in commercial or industrial facilities for process heat purposes. During the warm seasons, it is a beneficial solution for duties that need process heat at a temperature below $100^{\circ} \mathrm{C}$, even better below $50^{\circ} \mathrm{C}$. It can be used for various processes such as cleaning, washing, baths and vessels heating, drying, and pre-heating systems. Solar heat can be done using different types of undeveloped collectors. For instance: low-emissivity coated glazing, double glazed flat-plate collector (FPC) with anti-reflection, tightly sealed with vacuum or gas fillings, evacuated-tube collector (ETC) with reflectors, compound parabolic collector (CPC), parabolic trough collector (PTC), and Fresnel collectors [1-5]. A critical point must be considered: the solar system does not need to cover the total process heat demand, but cost optimisation is conducted to determine the optimum sizing.

Solar heat for domestic hot water production has an increasing observable market share globally. The international energy agency (IEA) expects solar array installations to provide $45 \%$ of the global demand in 2050 [6]. While currently in Europe solar heat process is in an early stage of market development, Hungary still has the lowest target for renewable energy compared to all other EU 
members [7]. The potential in Europe is enormous, where $27 \%$ of the final energy demand is needed for industrial heat and $30 \%$ of the overall industrial heat demand at a temperature level below $100^{\circ} \mathrm{C}$. It means that a significant part of this heat, mainly heat below $100^{\circ} \mathrm{C}$, can be produced by solar thermal plants with commercially available solar thermal collectors [8]. However, only 70 projects and installations in Europe were found according to the IEA task 33 titled "solar heat for industrial applications".

Such initiatives targeted the awareness raising for those who oversee industrial decision making. Also, to train professionals, planning guidelines, and conduct 12 pilot projects in Europe (mainly in 6 European regions Upper Austria, Madrid/Spain, Czech Republic, North-Rhine Westphalia and Saxony/Germany, Maribor /Slovenia) to encourage the utilisation of this technology. As a result, projects like Leitl Beton, Hörsching, Austria for prefabricated concrete ceilings with $1.91 \cdot 10^{6} \mathrm{MJ}$ annual production and the annual saving are more than $70 \%$. Also, Montesano, La Esperanza, Spain for meat derivates with $1.13 \cdot 10^{6} \mathrm{MJ}$ annual production and $45 \%$ solar fraction [9-10]. The solar fraction represents the ratio of the provided solar energy divided by the total required energy.

It is very important to size the storage tank to overcome the possible mismatch between the production peak and the thermal demand peak and reduce the wasted energy. Sizing the tank can be done directly or using reference data from textbooks [7]. Based on those references, $50 \mathrm{l} / \mathrm{m}^{2}$ of solar collector area can be used for the central European climate conditions. In contrast, $80 \mathrm{l} / \mathrm{m}^{2}$ can be used for regions with higher solar radiation, such as southern Europe.

Estimating the cost of the solar systems can be calculated, and it depends on the following five main elements: solar collectors, storage tank, piping system, auxiliary heaters, and heat exchangers [11].

It is necessary to classify the processes that consume thermal energy into open or closed processes, continuous or discontinuous processes. Suppose there is a continuous running open process with no mass or heat recovery. In that case, it should have the most significant attention since it has the highest potential for the integrations of the solar thermal system [12-13].

In recent years, analysis and simulation of solar thermal systems in both residential and civil sectors were analysed using several programs such as TYNSYS, Aspen-HYSYS, Python and MATLAB [14]. That research highlighted the attributed problems with the efficient use of solar systems from different prospects. The objective of the economic prospect is to minimise the costs, while the technical prospect is to maximise the overall system performance. At the same time, the environmental prospect is to minimise pollutant emissions. All prospects can be applied individually or collectively on the case study to achieve a better solar system.

In the literature, different approaches have been developed to design the solar thermal system. It varies in concept, such as detailed simulation like the day-to-day iterative method for 365 days per year like $T^{*}$ Sol. Or a more straightforward method like f-chart, which calculates the solar fraction during each month. Based on some sizing methods, choosing the collector area and the tank capacity is determined from a fixed share of the annual thermal load needed. This method assumes a fixed minimum and maximum shares as $40 \%$ and $60 \%$, respectively. It means that the solar system provided $60 \%$ of the total need during summer and reduced a bit (10-15\%) during the cold season.

Thermal efficiency and exergy analysis must be done for each component to achieve the optimum parameter. It can be by using Pinch analysis [12], system advisor model (SAM) [15], or using the audit methodology which was developed by the EINSTEIN project (Exert system for an INtelligent Supply of Thermal Energy In Industry) [16].

In this paper, two methods were conducted:

$\checkmark$ Changing one variable and detecting its magnitude on the overall solar fraction while the other system characteristics are defined;

$\checkmark$ The other is a linear modelling and optimisation process using the response surface method (RSM) to determine the most influential factors on the solar fraction. Based on the results, this research highlights the differences between the two methods to determine which method is better for optimising the SHIP system. The two methods will be compared with each other and with the other authors.

\section{MATERIALS AND METHODS}

In this research is modelled an indirectly forced circulation with external heat exchanger and primary flow loop with antifreeze fluid solar thermal system for heat process. The primary loop absorbs and transports the solar energy from the solar collectors to the hot side of the external heat exchanger. The assumed flow is a solution of glycol in water in different volume percentages to avoid freezing the primary fluid during wintertime. The 
external heat exchanger transfers the energy between the primary and secondary loop allowing the absorbed energy to pass to the heat storage tank. A temperature sensor checks the produced hot water from the solar system to see if it matches the desired water. If not, an auxiliary heating boiler warms the water to the desired level during the overcast days. Contrarily, when the water produced by solar exceeds the desired one, a 3-ways valve can add cold water to adjust the temperature.

Current studies are focusing on two different sets of simulations to optimise the system's performance. The first set is to perform and optimise the whole system performance for given characteristics of solar collectors. In contrast, the second one is to perform a simulation to optimise the efficiency of the solar collector. Most of those studies are done using TRNSYS or MATLAB software, and the scheme of the main components of the solar process heat system is shown in Fig. 1.

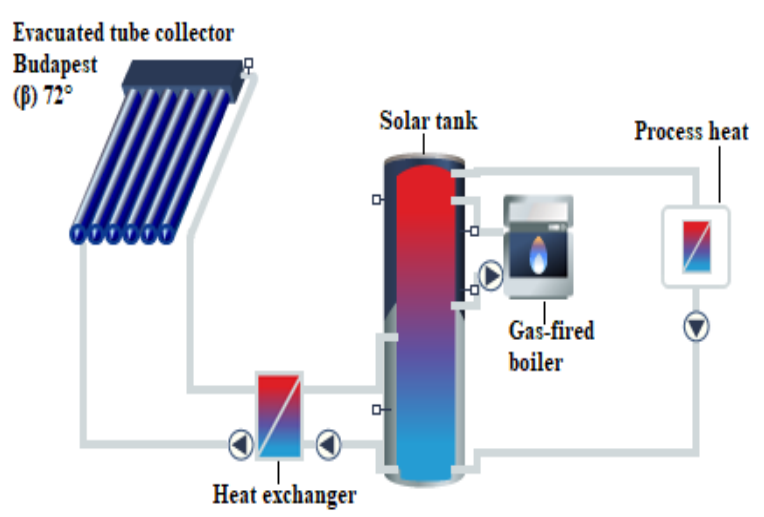

Fig. 1. Solar system for process heat

The working profile of the pasteurising plants is generally characterised for being continues through the year with short breaks, e.g., during Sundays where the work in half capacity, also during January and December when there are long vacations. In contrast, the daily profile differs since the pasteurising shift starts in the early morning at $6 \mathrm{AM}$ after the milking process. The plant works at $20 \%$ capacity until reaching the cleaning process at $4 \mathrm{PM}$. In the cleaning process, higher water temperature and flow are needed to clean the residuals in the system components that may cause health problems. Of course, not all pasteurising plants have the exact profile since it may differ if the company has different processes like packaging or cheese making. However, the studied profile concerns the primary process of all pasteurising plants.
The solar system is described considering the following parameters:

- Different sets of Evacuated-tube collectors

To optimise the overall system, an ETC is chosen with an $87.8 \%$ conversion ratio and $1.43 \mathrm{~W} / \mathrm{m}^{2} \mathrm{~K}$ and $0.0038 \mathrm{~W} / \mathrm{m}^{2} \mathrm{~K}^{2}$ simple and squared heat transfer coefficients. The heat transfer coefficients represent the thermal loss of solar collectors, which comes from the testing data. The dimensions of the collector are $2.14 \mathrm{~m}^{2}$ of gross area and $1.31 \mathrm{~m}^{2}$ of active area with a specific heat capacity of 8,000 $\mathrm{J} / \mathrm{kgK}$.

According to the solar electricity handbook, the collector needs to face the south with a tilting angle $(\beta)$ of $72^{\circ}$, the optimum angle for winter case in Budapest, Hungary.

- Collector loop heat exchanger

The mean logarithmic temperature difference (MLTD) is considered constant at $5 \mathrm{~K}$ for all cases. At the same time, the maximum heat transfer rate depends on the general size of the system, e.g., based on process heat requirements and the collector area. MLTD is usually used in flow systems to determine the temperature driving force for heat transfer.

- Unstratified tank

The tank has an insulation thickness of $100 \mathrm{~mm}$ of material with $0.065 \mathrm{~W} / \mathrm{mK}$ of thermal conductivity. At the same time, the expected average daily losses are $25.56 \mathrm{MJ} /$ day. The variable is the height to diameter ratio HT/D.

- Auxiliary heater

A gas-fired boiler is connected in parallel with the storage tank. Both the storage tank and tempering valve are set to the desired heat process temperature. And the capacity of the boiler is 191.16 MJ which is oversized since the boiler is not just needed for the duty, but also the space heating.

- Flow circulation pumps

The first one is mounted on the primary loop between the solar collector and the external heat exchanger, while the second is between the boiler and the storage tank, and the last is the process heat pump between the process and the storage tank. An on/off controller generates the signals for each pump; for example, the controller switches the primary loop if the outlet collector's temperature is above the tanks' temperature by $+8 \mathrm{~K}$ and switch off if it's below $+3 \mathrm{~K}$. The variables are the volume flow rate and the glycol-water volumetric ratio. 
- Internal and external connecting pipes

The external pipes are mounted between the collectors and the external heat exchanger, while the internal pipes are between the external heat exchanger and the buffer tank. The diameter is calculated based on $0.5 \mathrm{~m} / \mathrm{s}$ fluid flow velocity. In contrast, the thermal insulation is $0.045 \mathrm{~W} / \mathrm{mK}$ and it is $100 \%$ relative thickness of the pipe's nominal diameter.

- Weather and metrological data

The weather data are acquired between 1986 and 2005 and stored as external Typical Meteorological Year (MTY) files of Budapest-kmi weather station.

\section{RESULTS AND DISCUSSION}

\subsection{System optimisation using analytical method}

- Required collector area

The analytical model studied five different collector sets $5,10,15,20$, and 25 collectors. The other variables should be fixed at initial values at $0.05 \mathrm{~m}^{3} / \mathrm{m}^{2}$ relative tank capacity, the recommended value for solar heat for industrial processes in central Europe [11]. At the same time, the relative mass flow rate to each square meter of the collector area is $0.05 \mathrm{~m}^{3} / \mathrm{h} / \mathrm{m}^{2}$, which is within the recommended range in the literature [17]. In Hungary, using $30 \%$ glycol in water is considered a proper design to avoid freezing and bursting in the pipes. Finally, the tank's height-to-diameter ratio is $1.8 \mathrm{~m} / \mathrm{m}$. when this value increases, a higher daily loss will occur due to the larger exposed surface of the tank.

The result of the monthly solar fraction for each collector area is drawn in Fig. 2. The result shows that for indirect solar system with glycol solution, 20 ETC collectors, for each collector $2.14 \mathrm{~m}^{2}$ gross area, is a proper solution since the recommended value for industrial heating by solar is between $40 \%$ to $60 \%$ solar fraction, and this solution gives $48 \%$ annual solar fraction. This system is considered a proper design since it can provide more than $50 \%$ solar fraction from April till October, while it does not fall below $25 \%$ for the rest of the year. Moreover, considering the space requirements, costs, and reliability issues of large systems (for our case, approximately $43 \mathrm{~m}^{2}$ ), this system is a suitable design for industrial production in Budapest.

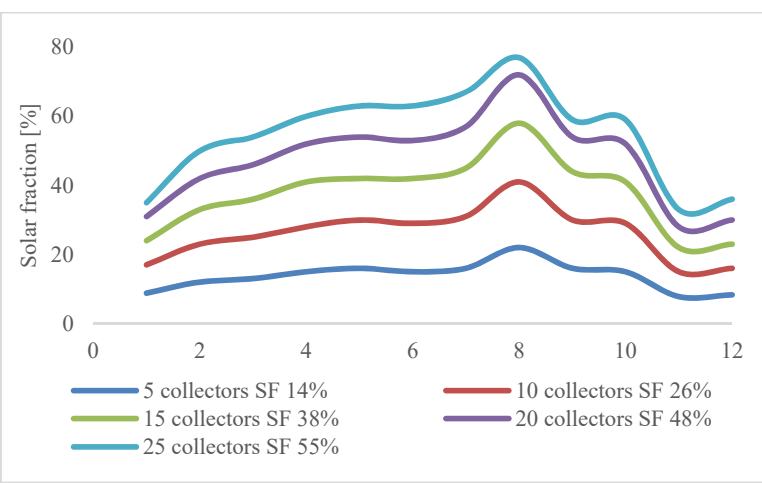

Fig. 2. Required collector area

On the other hand, this scope from another projection will result solar fraction increase step by step by adding five extra collectors. As in Fig. 3, adding more collectors than 25 will result in less than $5 \%$ solar fraction improvement. The results show that the above 25 collectors for this project have no significant output to the overall system performance.

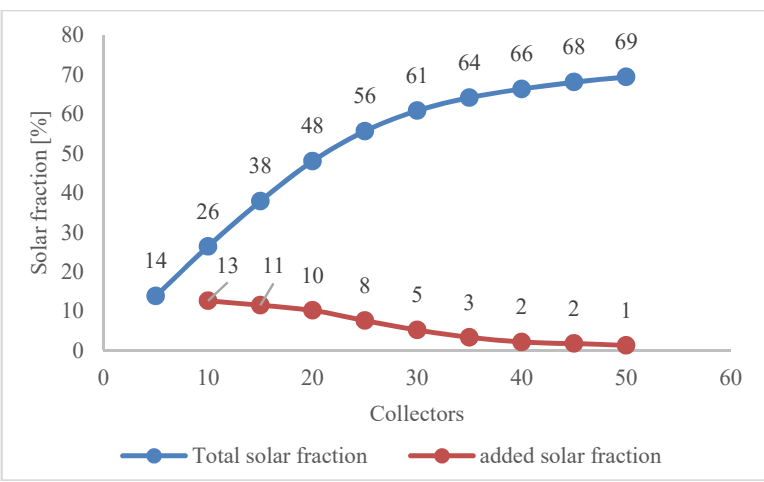

Fig. 3. Solar fraction Vs collector area

- Effect of glycol ratio in solution

The solution of polypropylene glycol-water is used in the solar system external loop to avoid freezing and burst problems. The specific heat of the glycol-water mixture varies with the volumetric percentage of the glycol in water and the temperature. Within the operating range of the collectors, the specific heat of $10 \%, 20 \%, 30 \%, 40 \%$, $50 \%$ glycol in water is $4,032,3,884,3,736,3,588$, and $3,440 \mathrm{~J} / \mathrm{kgK}$, respectively. Since the specific heat capacity of the glycol is less than the water, as the glycol ratio increases, a lower heat capacity of the total solution will occur. The simulation was conducted for different values of volumetric glycol ratio in water which varies between $5 \%$ and $60 \%$, to study the effect of polypropylene on the solar fraction. The results from the monthly prospect have no observable results since the graphs are overlapping, except during December and January, 
where this solution helps to harvest more solar during wintertime. But using annual solar fraction graphs helps identify the glycol mixture's importance in the solar loop. In Fig. 4, the annual solar fraction improves if more glycol is added up to $35 \%$. It is noted that $60 \%$ has similar overall performance, but $60 \%$ is recommended for cities where the ambient temperature falls to $223 \mathrm{~K}\left(-50^{\circ} \mathrm{C}\right)$ where solar is clearly not a feasible solution. The recommended values for Budapest, where the lowest recorded value was during January at 248.2 $\mathrm{K}\left(-25.6^{\circ} \mathrm{C}\right)$ and the corresponding recommended value for this case from literature is $46 \%$ glycol ratio for freezing protection or $30 \%$ for burst protection. Another reason to reject the $60 \%$ is the cost of this liquid, where the external loop must be filled with tens of litres of solution. As a result, the glycol ratio has no significant impact on the output. However, it must be taken from hydraulic prospect to ensure that no freezing or burst may happen in the solar system components.

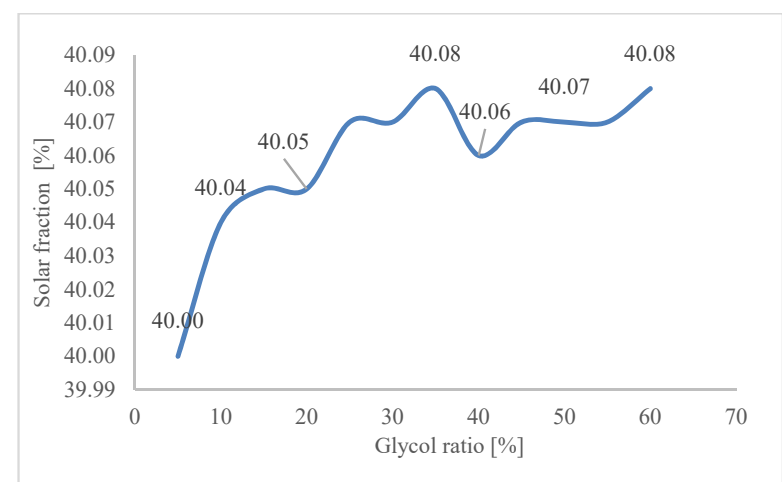

Fig. 4. Solar fraction Vs glycol ratio

- Effect of the collector mass flow rate

The effect of the collectors' flow rate $m / A_{c}$ ranges between 0.01 to $0.09 \mathrm{~m}^{3} / \mathrm{h} / \mathrm{m}^{2}$ on the monthly and annual solar fraction is simulated. The other variables were fixed at 16 collectors, 30\% glycol ratio, $0.05 \mathrm{~m}^{3} / \mathrm{m}^{2}$ solar tank volume and 1.8 height to diameter ratio. The variation of the solar fraction on the annual performance is plotted in Fig. 5. The optimum performance is between $0.02-$ $0.05 \mathrm{~m}^{3} / \mathrm{h} / \mathrm{m}^{2}$ and the peak at $0.03 \mathrm{~m}^{3} / \mathrm{h} / \mathrm{m}^{2}$. The monthly results show that the system approximately has more than $45 \%$ solar fraction from April till October while it does not fall below $25 \%$ but during November.

On the other hand, the flow rate can be kept constant between $0.02-0.04 \mathrm{~m}^{3} / \mathrm{h} / \mathrm{m}^{2}$ so that it will have no significant influence on the overall solar fraction. The optimum results found by this simulation agree with the previous research around
$0.036 \mathrm{~m}^{3} / \mathrm{h}$ [18-19] but with less impact on the solar fraction. For example, moving from 0.01 to 0.03 $\mathrm{m}^{3} / \mathrm{h} / \mathrm{m}^{2}$ will result in $6 \%$ more solar fraction for the indirect DHW solar system, while here, it will result in $2.18 \%$. This difference occurs because the two systems are different in boiler connection (direct, indirect) and the controlling method.

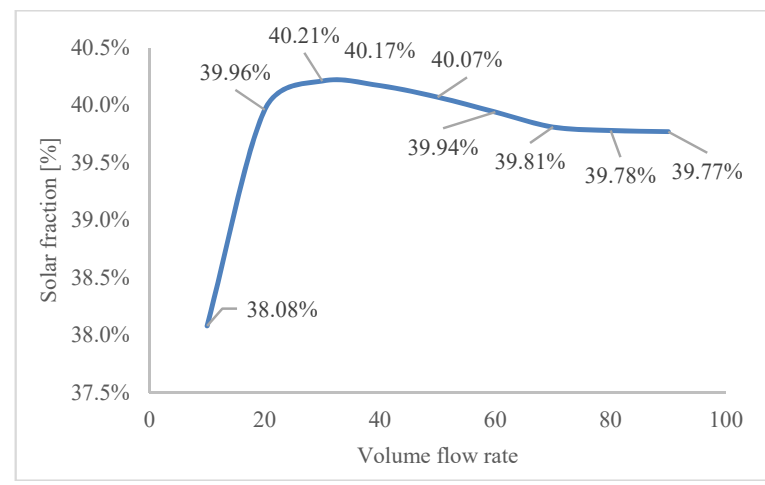

Fig. 5. Volume flow rate

- Effect of tank volume

The effect of the tank volume on the system performance is conducted for various tank-tocollector ratios $V_{c} / A_{c}$. At the same time, the other factors are fixed at 16 collectors, $30 \%$ glycol ratio, $0.03 \mathrm{~m}^{3} / \mathrm{h} / \mathrm{m}^{2}$ volume flow rate and 1.8 height to diameter ratio of the tank. As in Fig. 6, the result shows that the optimum ratio is $0.05 \mathrm{~m}^{3}$ for each square meter of the collector area. Suppose an increase of the tank's capacity from 0.01 to 0.05 $\mathrm{m}^{3} / \mathrm{h} / \mathrm{m}^{2}$ will gain a $12 \%$ additional solar fraction. This value matches precisely with the recommendations of the literature in the industrial sector [6]. If a continuous increase happens, then a negative impact on the overall system performance will appear. This difference is due to the increase of the heat losses from the storage tank to the surroundings because it will have a larger surface area. For $0.05 \mathrm{~m}^{3} / \mathrm{h} / \mathrm{m}^{2}$, the solar fraction is above $40 \%$ from April till October and does not fall below $23 \%$.

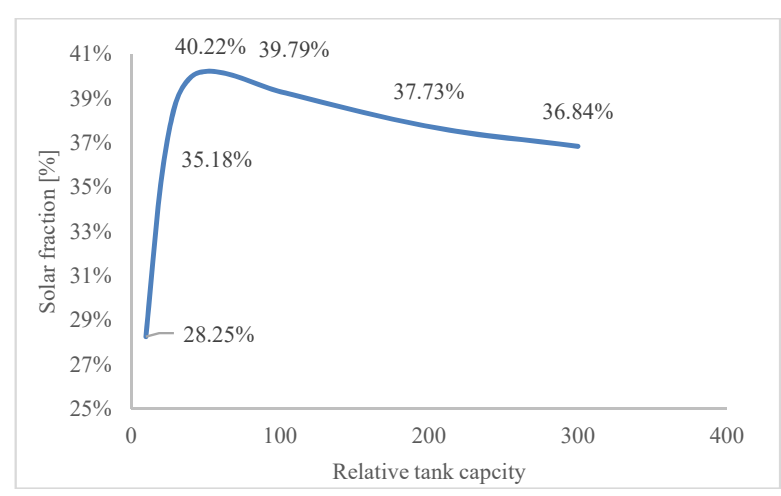

Fig. 6. Specific tank capacity 
- Effect of the tank height

The effect of the tank height on the overall system performance is studied for 16 collectors, 30\% glycol ratio, $0.03 \mathrm{~m}^{3} / \mathrm{h} / \mathrm{m}^{2}$ volume flow rate and $0.05 \mathrm{~m}^{3} / \mathrm{m}^{2}$ solar tank volume. Fig. 7 presents the relationship between the annual solar fraction and the tank's height. It shows that the annual solar fraction increases when the height-to-diameter of the tank increases from 0.2 to $1 \mathrm{~m}$. Then it remains at slightly constant values till $1.8 \mathrm{~m}$, and then it starts to decrease since the heat losses will increase due to the larger exposed surface area. Similar to other graphs, it is noted that the monthly solar fraction remains above $40 \%$ from April till October, while it is above $23 \%$ for the rest of the year (wintertime).

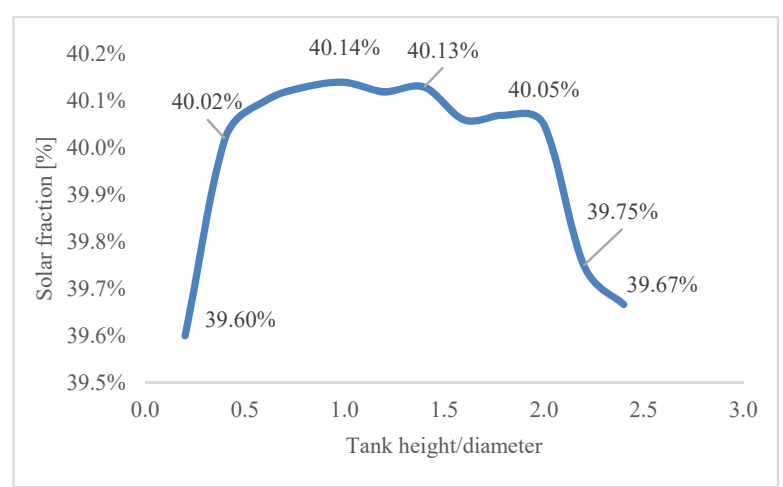

Fig. 7. Tank height to diameter ratio

\subsection{System optimisation using RSM and R script}

Analytical methods are suitable for having a deeper look at the system, considering each factor as an independent variable. Since when the single variables are evaluated, the other variables are set at a specific medium level. But is the effect of this factor being the same when the other variables are at different levels? In other words, the analytical methods are not sufficient to make a final judgment regarding the factors that most significantly influence the desired goal (solar fraction or system efficiency), considering that other factors are changing simultaneously.

For this purpose, a complete set of experiments was conducted considering all the variables' fluctuation simultaneously. The experiment has five variables, which means a set of $2^{\mathrm{K}}$ (where $k$ is the number of variables). It equals $2^{5}=32$ full factorial experiments for each factor at two coded levels $[-1$, +1 ]. Each level has a corresponding real value which can be converted using the Eq. 1. The real values are in Table 1.

$$
\text { coded value }=\frac{\text { real value-center value }}{\frac{1}{2}(\text { range })}, \quad 1
$$

Table 1. Set of actual experiment values

\begin{tabular}{|c|c|c|c|c|}
\hline \multirow{2}{*}{ Variable } & \multicolumn{2}{|c|}{ Coded value } & Unit \\
\cline { 3 - 5 } & -1 & +1 & \\
\hline A & collector area & 5 & 25 & Collectors \\
\hline B & Glycol ratio & 10 & 60 & $\%$ \\
\hline C & Mass flow rate & 0.01 & 0.07 & $\mathrm{~m}^{3} / \mathrm{h} / \mathrm{m}^{2}$ \\
\hline D & Tank volume & 0.01 & 0.07 & $\mathrm{~m}^{3} / \mathrm{m}^{2}$ \\
\hline E & $\begin{array}{c}\text { Tank } \\
\text { height/diameter } \\
\text { ratio }\end{array}$ & 0.4 & 1.6 & $\mathrm{~m} / \mathrm{m}$ \\
\hline
\end{tabular}

The modelling process using the R-script program was created for the abovementioned values using a linear model. A simulation process using $T^{*}$ sol is conducted for each case to determine the corresponding case's solar fraction and system efficiency.

The linear approach is the least-squares method, which was invented by Carl Friedrich Gauss back in 1795. This approach provides the rationale for the best fit line placement that crosses among the studied data points. To easily observe the results, the magnitude of each parameter is presented using the Pareto plot as in Fig. 8. In the Pareto plot, the influence of every parameter on the solar fraction is observed and all other interactions from second, third, fourth and fifth degrees. But while more than two factors do not exist in nature, the most critical magnitudes are only considered to make better visualisation in the Pareto plot

As a result, the most crucial single positive factors are $A, D$, and $E$, representing the collector area, tank volume, and the tank height/diameter ratio by $16.5 \%, 3.6 \%$, and $0.45 \%$, respectively. In overall prospect, changing factor $\mathrm{A}$ (the required collector area) from 5 to 25 collectors will add $16.5 \%$ solar fraction to the system compared to $42 \%$, as illustrated by the analytical method in Fig. 3 . Similarly, moving from 0.01 to $0.07 \mathrm{~m}^{3} / \mathrm{m}^{2}$ will add $3.6 \%$ to the solar fraction compared to $11.75 \%$, as in Fig. 6. Finally, moving from 0.4 to 1.6 tank height/diameter ratio will add approximately $0.45 \%$ to the solar fraction compared to $0.04 \%$, as in Fig. 7 . In contrast, the negative single factor magnitudes are $\mathrm{B}$ and $\mathrm{C}$, representing the Glycol ratio and the mass flow rate by $-0.49 \%$ and $-0.05 \%$, respectively. Moving from $10 \%$ to $60 \%$ glycol ratio will decrease the solar fraction by $0.49 \%$, while in the analytical method, it shows a slight increase by $0.04 \%$, as in Fig. 4. Similarly, the mass flow rate decreases by 
$0.05 \%$ while moving from 0.01 to $0.07 \mathrm{~m}^{3} / \mathrm{h} / \mathrm{m}^{2}$ compared to an increase of $1.73 \%$, as in Fig. 5 . In conclusion, those differences between the two methods are because the analytical method considers the other variables at a specific level. In contrast, RSM considers the overall changing of all factors at the same time.

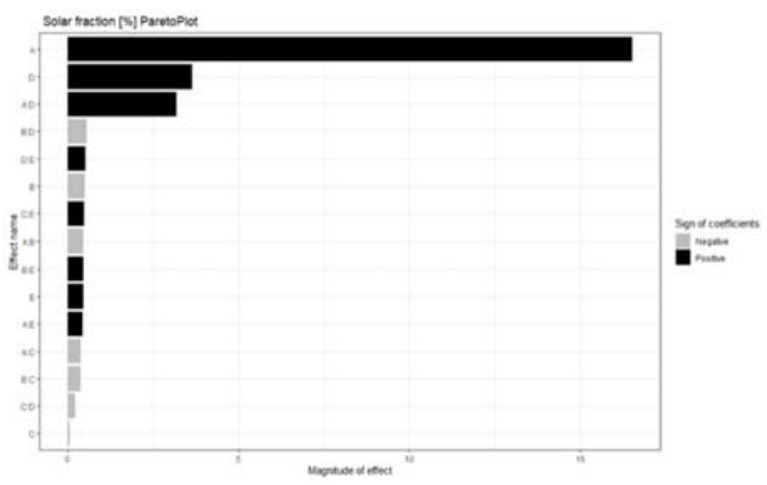

Fig. 8. Solar fraction Pareto plot

The most influential two factors interaction will be considered using the Pareto plot. It is noticed that $A: D$ and $D: E$ have a positive magnitude of $3.17 \%$ and $0.52 \%$, and $B: D$ has a negative magnitude of $-0.55 \%$. The most influential two factors are $A: D$ which means the interaction between the collector area and the tank volume. It means if 25 collectors and $0.07 \mathrm{~m}^{3} / \mathrm{m}^{2}$ were chosen, it would add a $3.17 \%$ additional solar fraction. It is observed in Fig. 9, where the best solar fraction can be achieved in the upper right of the graph where both $A$ and $D$ are positive magnitudes.

Similarly, the D:E interaction represents the tank volume with the tank height/diameter ratio. It has a positive magnitude of $0.52 \%$, which occurs when both $D$ and $E$ are in positive values where the upper right side shows a higher solar fraction. In contrarily, B:D interaction has a negative magnitude, representing the glycol ratio and the tank volume, by $-0.55 \%$. It means the best is to choose one factor positive and the other one negative so the overall will be positive. As clearly, the graph shows, the best solar fraction happens in the upper left part where $B$ is negative, and $D$ is positive, which means having a low glycol ratio and high tank volume.

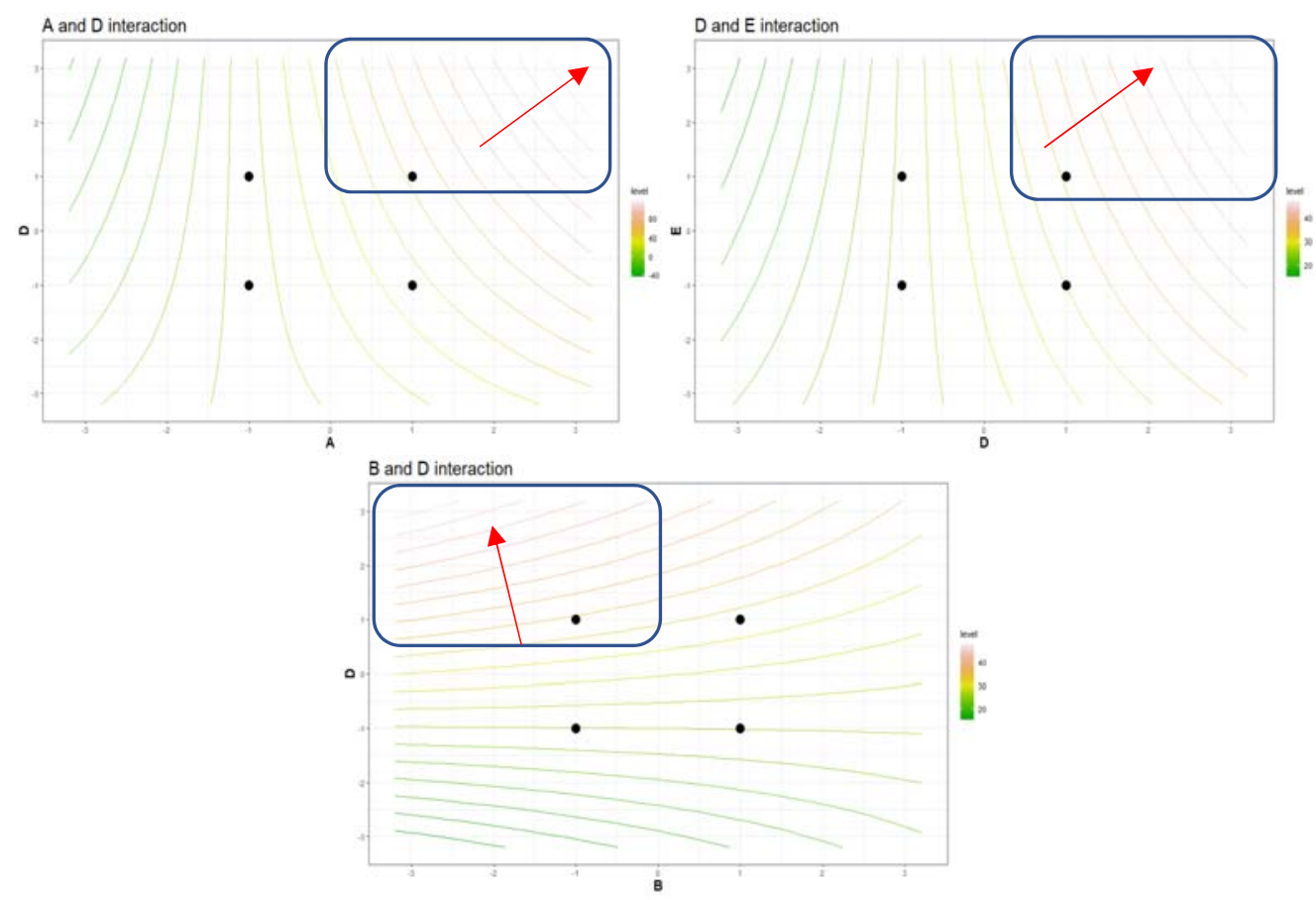

Fig. 2. Two factors interaction

\section{CONCLUSION}

In central Europe, diary factories exist widely and have a massive demand for hot water for pasteurising and cleaning purposes during the daytime, with approximately continuous consumption profiles during the year. Even though those factories still rely on electricity to generate hot water, solar thermal systems like FPC or ETC can provide an essential portion. This paper presents analytical and mathematical modelling methods of five crucial factors (collector area, glycol ratio, relative mass flow rate, tank capacity, and tank height/diameter ratio) for optimising solar thermal 
system used for the process heat generation in a pasteurising plant located in Budapest, Hungary. The umpire factor was the solar fraction, where the two methods were compared, and the differences in the results were highlighted and discussed in detail. The analytical method can highlight the magnitude of only a single variable, and it clearly shows the interval of the optimum value. In contrast, the other variables are fixed at a specific level.

On the contrary, RSM using the least square method and linear modelling using $R$ script studies the magnitude of the variables on the system when the other variables change. It can also give a general prospect of the variable using the Pareto plot. Also, it provides each two-factor magnitude using twofactors contour graphs. These two methods were never compared in the literature to highlight the pros and cons of each one. This comparison will help to optimise SHIP systems. As a result, the collector area has the highest positive magnitude in both methods followed by relative tank capacity and tank height to diameter ratio, respectively. In contrary, glycol ratio was the only negative magnitude in both approaches. On the other hand, relative flow rate showed relatively neutral behaviour on RSM compared to positive magnitude on the analytical method.

\section{REFERENCES}

[1] F. Elimar, S. Hess, C, Zahler, General requirements and relevant parameters for process heat collectors and specific collector loop components. IEA SHC and SolarPACES, 2012.

[2] A. Hajipour, E. Shojaeezadeh, S.K. Asadi Yousef-abad, K. Goudarzi, Experimental investigation of thermal performance in an advanced solar collector with helical tube, International Journal of Engineering, Transactions A: Basics, 27 (7), 2014: 1149-1154.

[3] W. Weiss, M. Rommel, Process Heat Collectors. State of the Art within Task 33/IV, IEA SHC-Task 33 and SolarPACES-Task IV: Solar Heat for Industrial Processes. IEA and AEE INTEC, Gleisdorf, 2008.

[4] P. Horta, Process Heat Collectors: State of the Art and available medium temperature collectors. IEA SHC and SolarPACES, 2016.

[5] Š. Škrbić, A. Ašonja, R. Prodanović, V. Ristić, G. Stevanović, M. Vulić, Z. Janković, A. Radosavac, S. Igić, Analysis of Plant Production Obtained Biomass in Function of Sustainable Energy. Sustainability, 12 (13), 2020: 5486. https://doi.org/10.3390/su12135486

[6] S. Mekhilef, R. Saidur, A. Safari, A review on solar energy use in industries. Renewable and Sustainable Energy Reviews, 15 (4), 2011: 1777-1790.

https://doi.org/10.1016/j.rser.2010.12.018

[7] D.Y. Goswami, F. Kreith, Energy Efficiency and Renewable Energy Handbook. CRC Press, Boca Raton, USA, 2015. https://doi.org/10.1201/b18947

[8] S.Heß, A. Oliva, Solar Process Heat Generation: Guide to Solar Thermal System Design for Selected Industrial Processes. O.Ö. Energiesparverband, Linz, Austria, 2011.

[9] K. Hennecke, B. Hoffschmidt, W. Meinecke, M. Blanco, The Future for Renewable Energy 2: Prospects and Directions, Solar process heat, 222-230, Routledge, Great Britain, 2013.

[10]B. Schmitt, S. Hess, "Best practice" Series of Case Study Reports from Demonstration Projects, IEA SHC and SolarPACES, 2016.

[11] A. Franco, Methods for the sustainable design of solar energy systems for industrial process heat. Sustainability, 12 (12), 2020: 5217. https://doi.org/10.3390/su12125127

[12] C. Brunner, B. Slawitsch, K. Giannakopoulou, H. Schnitzer, Industrial Process Indicators and Heat Integration in Industries. Joanneum research, Graz, Austria, 2008.

[13] A. Ašonja, E. Desnica, Lj. Radovanović, Energy Efficiency Analysis of Corn Cob Used as a Fuel. Energy Sources, Part B: Economics, Planning and Policy, 12 (1), 2017: 1-7.

http://doi.org/10.1080/15567249.2014.881931

[14] L. Kumar, M. Hasanuzzaman, N.A. Rahim, Global advancement of solar thermal energy technologies for industrial process heat and its future prospects: A review. Energy Conversion and Management, 195, 2019: 885-908. https://doi.org/10.1016/j.enconman.2019.05. 081

[15] N. S. Suresh, B. S. Rao, Solar energy for process heating: A case study of select Indian industries. Journal of Cleaner Production, 151, 2017: 439451.

https://doi.org/10.1016/j.jclepro.2017.02.190

[16] C. Brunner, B. Muster-Slawitsch, E. Heigl, H. Schweiger, C. Vannoni, EINSTEIN - Expert System for an Intelligent Supply of Thermal Energy in Industry - Audit Methodology and Software Tool. Chemical engineering transactions, 21, 2010: 685-690. https://doi.org/10.3303/CET1021115 
[17] J.A. Duffie, W.A. Beckman, Solar Engineering of Thermal Processes. John Wiley \& Sons, Inc., New Jersey, USA, 2013. https://doi.org/10.1002/9781118671603.app1

[18] A. Hobbi, K. Siddiqui, Optimal design of a forced circulation solar water heating system for a residential unit in cold climate using TRNSYS. Solar Energy, 83 (5), 2009: 700-714. https://doi.org/10.1016/j.solener.2008.10.018

[19] R. Majumdar, S.K. Saha, A. Patki, Novel dimension scaling for optimal mass flow rate estimation in low temperature flat plate solar collector based on thermal performance parameters. Thermal Science and Engineering Progress, 19, 2020: 100569.

https://doi.org/10.1016/j.tsep.2020.100569 